\title{
Da crítica diplomática à análise tipológica: abordagens e técnicas de análise documental
}

\author{
From diplomatics criticism to contemporary diplomatics analysis:
} approaches and tech-niques of documentary analysis

\author{
Sonia Troitiño RODRÍGUEZ \\ Departamento de Ciência da Informação, Faculdade de Filosofia e Ciências, Universidade Estadual Paulista, Brasil \\ stroitino@globo.com
}

\begin{abstract}
Resumen
Este estudio, de naturaleza instrumental, se discuten las diferencias teóricas entre los modelos de análisis documental empleados por la Diplomática tradicional y por la Tipología Documental. Sin duda, ambos modelos de análisis contribuyen a la comprensión de las fuentes - punto vital del proceso de crítica documental que se emplea en cualquier área del conocimiento. Así, la elección de una u otra técnica de análisis depende de los objetivos de la investigación, de acuerdo con el objeto que se adopta por referencia: la serie documental o el documento individualizado. De esa manera, temas como el valor probatorio y la autenticidad son de extrema importancia para la Archivística, que busca por medio de sus disciplinas auxiliares verificar la trayectoria del documento, desde el momento de su producción, tramitación y archivamiento hasta sus diferentes custodias, contribuyendo en mucho para la comprensión de la información - tanto la registrada como la de contexto- en un sentido más amplio.
\end{abstract}

Palabras clave: Diplomática. Archivística. Tipología Documental. Análisis Documental.

\section{Introdução}

Do seu surgimento no século XVII aos dias atuais, a diplomática vem transformando-se e readequando-se de acordo com as necessidades de cada período. Procuraremos aqui traçar algumas das possibilidades e usos da diplomática desde sua origem até aos dias de hoje focando, em especial, no emprego de seus critérios no processo de análise aplicado à tipologia documental. Com esse objetivo, nos parece pertinente recuperar os conceitos fundamentadores da disciplina, posto constituir ponto crucial para o estabelecimento da espécie documental termo amplamente difundido no Brasil para designar a configuração que assume um documento de acordo com a disposição e a natureza das informações nele contidas (Camargo, 1996) -e do tipo documental.

Em uma primeira parte, pretendemos expor alguns dos conceitos fundamentais da diplomática, em especial no que tange aos aspectos

\begin{abstract}
This study, of an instrumental nature, discusses the theoretical differences which underpin the documentary analysis models used in traditional Diplomatics and Contemporary Diplomatics. Undoubtedly, both models of analysis contribute to the understanding of the sources - a vital point of the process of analyzing the document to be used in any area. Thus, the choice of either technique must take into account the goals proposed for the research, according to the object that is taken as the reference point: the archival series or the individual document. That way, issues such as the evidential value and diplomatic authenticity are important within the Archival Science, which seeks through auxiliary disciplines to verify the historical trail of the document, from the moment of its production, usage and archiving, as well as the various custodians, contributing in a large measure to the understanding of its information - what is registered as well as the context- in its broadest sense.
\end{abstract}

Keywords: Diplomatics. Archival Science. Contemporary Diplomatics. Documentary Analysis.

conceituais absorvidos da disciplina e sua releitura contemporânea, levando em consideração a arquivística atual, para isso, este artigo se alinha ao paradigma arquivístico moderno expressado pela teoria de Luciana Duranti e pelas considerações de Heather MacNeal e Bruno Delmas a respeito. Assim como também se pauta nos trabalhos desenvolvidos por Heloísa Liberalli Bellotto e Antonia Heredia Herrera no que diz respeito ao surgimento e consolidação da tipologia documental enquanto campo de estudo.

A tipologia documental, por alguns pesquisadores também chamada de diplomática contemporânea, caracteriza-se pelo deslocamento do foco de análise do documento isolado para o documento orgânico. Parte do uso da Diplomática clássica, mas diferencia-se em relação ao seu objeto e à recuperação de informações decorrentes do contexto de produção documental e das relações orgânicas as quais privilegia 
-ponto fulcral dentro da arquivística. Deste modo, faz-se necessário discutir dentro destas perspectivas, o conceito de documento diplomático e de documento arquivístico aqui adotados, por estes constituírem-se objeto de análise.

Procura este trabalho, demarcar as diferenças metodológicas entre a crítica diplomática e a análise tipológica. Assim, diante de um documento de arquivo, qual técnica de análise documental empregar? Tendo em conta que a abordagem empregada na análise documental acaba por direcionar o encaminhamento dado ao trabalho arquivístico a ser desenvolvido, é fundamental que a eleição do método leve em consideração os atributos do documento, tais como autoridade, completeza, assinatura, organicidade, credencial de segurança, o contexto jurídico-administrativo e o contexto de proveniência.

\section{Bases da Diplomática}

Ainda que, originalmente, a diplomática, enquanto disciplina, tenha surgido durante a Idade Moderna com o intuito de analisar criticamente e verificar a autenticidade de documentos medievais, atualmente vem sendo reconhecida por diversos autores como instrumento útil à análise de documentos modernos e contemporâneos, na medida em que o emprego de seus conceitos e técnicas de análise permite o reconhecimento de padrões e fórmulas jurídicas adotadas no registro do ato.

Tomando por base a unidade documental, a diplomática preocupa-se em estudar criticamente o fato e a vontade que a origina, em relação ao propósito e à consequência. Da mesma forma, preocupa-se com o desenvolvimento de seu processo genético, assim como das características de sua forma física e intelectual. A diplomática se esforça em averiguar a autenticidade, a validade e a autoridade, da mesma forma que a plena compreensão do conteúdo, através da observação dos distintos elementos constitutivos do documento, sem que isso represente uma preocupação específica sobre o assunto tratado.

A noção diplomática de autenticidade é particularmente útil para o pesquisador porque requer que os documentos sejam analisados em termos de sua composição física e conteúdo. Volta-se ao estudo da estrutura formal e à determinação da autenticidade de um documento, com o objetivo específico de verificar a confiabilidade dos fatos. Evidentemente que isto não denota neutralidade documental. O registro documental não deve ser entendido como sinônimo de verdade ou realidade, mas sim assentamento - assentamento de uma ação derivada da necessidade de se registrar uma atividade.

Compõem o conceito de autenticidade dois importantes elementos: identidade e integridade. Segundo Duranti (1996), a identidade diz respeito aos atributos apresentados por um documento para torná-lo único (pessoas envolvidas, datas de criação e transmissão, relações arquivísticas, etc.), e é justamente a não adulteração desses atributos que lhe confere a integridade.

Como bem expõe MacNeal (2001), um documento autêntico é aquele que é o que diz ser, não havendo sido corrompido ou falsificado desde o momento de sua criação. Nesse sentido, a autenticidade diz respeito ao valor de verdade de um registro enquanto manifestação física dos fatos fixados em algum suporte e deve ser avaliado em relação à instância original do documento.

A noção de autenticidade para a diplomática se distingue da de veracidade. A veracidade diz respeito ao teor informacional das afirmações contidas no documento, enquanto que a autenticidade é confirmada através de sinais de validação. Delmas (2003) comenta que a veracidade do documento pode ser comprovada por sua inserção no contexto histórico, por sua comparação com outras fontes e também pelo uso de elementos do estudo da gênese e da tradição.

A propósito, os sinais de validação fazem parte justamente de um mecanismo criado para se evitar possíveis fraudes e conferir autenticidade a um documento. Assim, selos, carimbos, qualidade e tipos de papel, timbres, marcas d'água, assinaturas, rubricas, são alguns dos elementos observados pela crítica externa, aplicada durante a análise diplomática, justamente para que seja verificado o grau de fidedignidade documental. É claro que estes sinais não são provas invioláveis, no entanto constituem, sim, elementos de autenticidade e devem ser observados meticulosamente, pois eles podem tanto garantir a integridade do documento quanto apresentar sinais de falsificação.

Uma das principais questões contempladas pela diplomática é justamente o estabelecimento da autoridade de um documento. Se a autoridade refere-se à atribuição, ou seja, à capacidade e ao poder da pessoa que produz o documento em fazê-lo, a validade do documento é geralmente a medida do grau em que formato físico e a articulação interna da informação se conformam para atender a um objetivo específico: a ação traduzida em registro. 


\section{Documento diplomático, documento arquivístico}

Para Duranti (1996), o objeto da diplomática não é qualquer documento escrito que se estude, mas somente o documento arquivístico, ou seja, um documento criado ou recebido por pessoa física ou jurídica no exercício de uma atividade administrativa. Desta forma, volta seu estudo da teoria diplomática aos documentos que surjam de uma atividade prática dentro da dinâmica organizacional, seja pública ou privada, isto é, volta-se para os documentos arquivísticos e às circunstâncias de sua criação.

Já para Bellotto (2002, p.27), o objeto da diplomática é a espécie documental, por considerá-la como "aquela que obedece a fórmulas convencionadas, em geral estabelecidas pelo direito administrativo ou notarial". Desse modo, mesmo que a diplomática se volte para o estudo da unidade documental, a introdução dessa técnica de análise no campo da arquivística possibilita um reexame do objeto de análise: o documento de arquivo.

É importante sempre ter no horizonte que o documento de arquivo não é uma unidade isolada, autônoma, mas em relação orgânica direta com as demais unidades documentais do fundo. Quando essas unidades documentais derivam de uma mesma atividade, podem ser agrupadas em séries, definidas pelo tipo documental que representam.

O tipo documental, entendido como a configuração que assume uma espécie documental de acordo com a atividade que a gerou, decorrente de uma função específica dentro de uma entidade, é o objeto da tipologia documental. De acordo com Bellotto (2004, p.123):

As séries documentais que refletem operações, atividades, funções e competências definem-se por sua tipologia, e esta denota a identidade de cada um de seus documentos componentes.

Posta esta diferença, ao deslocar o foco de análise da unidade documental para a série arquivística, ou seja, para o conjunto de documentos de características semelhantes de produção e registro, a metodologia empregada para tal análise também deve ser distinta.

Delmas (1996) expõe que, de acordo com a definição clássica, um documento arquivístico é definido por sua proveniência e vai ao encontro aos usos que originaram sua criação e acumulação, independentemente de data, forma, formato ou suporte. Acredita que este entendimento de arquivos por funções é aplicável a todos os documentos, sejam contemporâneos ou não e compreende igualmente desde registros em papel, manuscritos, impressos ou rascunhos; a fotografia, filmes a registros sonoros, discos magnéticos ou óticos, ou qualquer outro registro da informação. A natureza do documento não é determinada por sua forma, suporte físico, data ou gênero documental, mas sim pelas relações que estabelece com seu contexto de produção e devem obrigatoriamente incluir o conceito de informação orgânica. É importante relembrar que documentos arquivísticos são também caracterizados pelo motivo de sua criação, por seu caráter probatório e que constituem pontos vitais no processo de tomada de decisão, tornando-se simultaneamente instrumentos de uma ação, devido ao seu uso, e registro da ação.

Considerando estas questões, o entendimento do documento eletrônico como documento de arquivo, seguindo os mesmos pressupostos do documento convencional, ganha espaço. Os requisitos necessários para garantir a estabilidade e confiabilidade da informação, assim como sua preservação em frente aos rápidos avanços tecnológicos que tornam meios, mídias e sistemas obsoletos em curtos espaços de tempo vêm sendo recorrentemente tratado por inúmeras pesquisas e iniciativas das áreas de Ciência da Informação e Tecnologia da Informação. Nesse novo contexto, concepções como autenticidade, genuinidade e veracidade, ganham nova roupagem adaptando-se às necessidades de manutenção da confiabilidade da informação (Duranti,1996; MacNeil, 2000).

Resultados de projetos, como os encampados pela University British Columbian (UBC), The Preservation of The Integrity of Electronic Records e o InterPARES (International Research on Permanent Authentic Records in Electronic Systems), foram amplamente divulgados afirmando que os elementos contidos nos documentos eletrônicos assemelhavam-se aos documentos convencionais, por isso mesmo eram passíveis de serem revestidos de sinais de validação que Ihes conferissem autenticidade e os vinculassem ao contexto de produção documental de ambientes físicos. Ou seja, a desmaterialização do documento não significaria a quebra do princípio de proveniência, nem dos vínculos orgânicos que o conectam a outras unidades do mesmo fundo, sejam elas eletrônicas ou não.

Atualmente o InterPARES encontra-se em sua terceira fase, a qual consiste em colocar na prática as teorias e metodologias pesquisadas durante as duas primeiras fases, ocorridas entre os anos de 1999 e 2007, e projetar em nível mundial essas iniciativas de preservação digital. No Brasil, a ramificação do InterPARES é liderada pelo Arquivo Nacional e o grupo responsável pelo desenvolvimento do projeto, denomina- 
do TEAM Brasil, e tem se voltado para a transposição da teoria e a metodologia de preservação digital, desenvolvida pelo próprio InterPARES e por outras ações de pesquisa, em planos concretos de ação para arquivos.

Uma das iniciativas brasileiras nessa área de estudo foi o projeto e-ARQ Brasil. O e-ARQ Brasil é um projeto desenvolvido pela Câmara Técnica de Documentos Eletrônico do Conselho Nacional de Arquivos (CONARQ) dentro do Arquivo Nacional do Brasil entre 2004 e 2006, para o estabelecimento especificações de requisitos para sistemas informatizados de gestão arquivística de documentos e pelos próprios documentos para a organização produto$\mathrm{ra} /$ recebedora de documentos visando a garantir sua confiabilidade e autenticidade, assim como o acesso. Serve também para orientar a identificação de documentos arquivísticos digitais.

Segundo definição estabelecida pelo e-ARQ Brasil (2006):

Documento arquivístico convencional é um documento arquivístico produzido, tramitado e armazenado em formato não digital.

Documento arquivístico digital é um documento arquivístico codificado em dígitos binários, produzido, tramitado e armazenado por sistema computacional. São exemplos de documentos arquivísticos digitais: textos, imagens fixas, imagens em movimento, gravações sonoras, mensagens de correio eletrônico, páginas web, bases de dados, dentre outras possibilidades de um vasto repertório de diversidade crescente.

É importante notar que, para que esses documentos eletrônicos se tornem passíveis de serem seriados e submetidos à classificação arquivística, devem conter todos os elementos pertencentes a um documento de arquivo, proveniência e organicidade bem definidas, dentro de um quadro de funções e atividades, decorrentes das competências e atribuições estabelecidas pela entidade da qual decorrem.

\section{Tipologia documental: possibilidades da diplomática contemporânea}

Nas últimas décadas, houve um alargamento dos conceitos e da utilização da diplomática e, atualmente, ela vem sendo empregada em larga medida na análise de documentação arquivística, com o objetivo de recuperação do contexto funcional da produção documental.

Hirtle (2000) comenta que a teoria arquivística tradicional desenvolveu duas abordagens para assegurar a autenticidade do documento e que estas unidas são capazes de assegurar a autenticidade dos registros no mundo análogo. A primeira abordagem, foca o documento individualizado, considerando que o seu formulário e as circunstâncias de sua criação são capazes de garantir a confiabilidade do registro. A segunda abordagem, procura compreender e controlar o contexto de produção documental, tendo por premissa que registros gerados por uma entidade e transferidos dentro de um plano de gestão arquivística adequado, presumidamente devem ser autênticos.

Seguindo a mesma linha de pensamento, Heloísa Bellotto (2002, p. 13) afirma que:

Não é possível dissociar a diagramação e a construção material do documento do seu contexto jurídico-administrativo de gênese, produção e aplicação.

Em outras palavras, a configuração assumida pelo registro produz uma fórmula específica, representada por forma, formato, gênero, suporte e sinais de validação, todos elementos extrínsecos ao documento que, aliados aos intrínsecos -autor, datação, origem, tradição- expressam o tipo diplomático.

Sobre a relação entre diplomática e tipologia documental, é possível entender esta última como (Bellotto, 2002, p.19-20)

a ampliação da diplomática em direção à gênese documental, perseguindo a contextualização nas atribuições, competências, funções e atividades da entidade geradora/acumuladora..

Enquanto que a diplomática tem por objeto a configuração interna do documento, o estudo jurídico de suas partes e dos seus caracteres para atingir sua autenticidade, a tipologia documental ultrapassa esse limite agregando a seu objeto o estudo de componentes relativos ao conjunto orgânico, ou seja, se preocupa com a relação estabelecida entre os integrantes de uma mesma série documental, levando em conta 0 fato de esses documentos serem correspondentes à mesma atividade.

Nos últimos anos, o estudo da tipologia documental vem sendo chamado por alguns estudiosos de "diplomática contemporânea", constituindo assim uma nova área, produto da revisão e da atualização dos princípios importados da diplomática clássica. Rodrigues (2008, p. 153) detecta que:

No campo da ciência arquivística, a diplomática tem sido reinventada, adaptada como uma ferramenta para compreender o complexo processo de produção dos documentos da burocracia contemporânea. Rodrigues.

Isto se deve, em larga medida, à ampliação do campo de atuação da arquivística, já não mais limitada à massa acumulada, mas fazendo-se 
presente em todas as etapas do ciclo de vida dos documentos. Por conseguinte, tornou-se inevitável o desenvolvimento de metodologias que dessem suporte aos novos programas arquivísticos, entre eles a avaliação e o controle da produção documental.

Assim, os princípios, conceitos e métodos da diplomática podem oferecer subsídio ao estudo arquivístico das espécies documentais. Duranti (1996) recomenda que o arquivista extraia diretamente da ciência diplomática original elementos e ideias que possam ser usados para seu trabalho e desenvolvidos para que sejam aplicados às necessidades contemporâneas. Delmas (2003) corrobora com essa posição, argumentando que o conhecimento da gênese e da tradição, pontos cruciais da crítica diplomática, ajuda a situar o documento e a reconhecer seu grau de autenticidade. Para que isto aconteça, é essencial a realização de uma crítica interna que abranja a tipologia documental, o seu discurso, o tipo de atividade e a idéia de que o documento trata.

O tipo documental, peça chave da abordagem tipológica analítica, não deve ser confundido com a própria unidade documental. De acordo com Heredia (2007), o tipo deve refletir um "modelo ideal", pautado no elo existente entre a espécie e a função geradora do documento, consequência natural do registro de uma atividade, estabelecendo um padrão a ser empregado. Podemos considerar o tipo documental como parâmetro para o reconhecimento de outros documentos com características semeIhantes de produção e tramitação. Nesse sentido, o tipo documental, pode ser entendido como uma estrutura básica a ser utilizada no registro de uma atividade específica. Ao contrário da unidade documental, é desprovido de data cronológica por ser representativo da atividade e não do fato em si.

Tendo em conta estes aspectos, é importante notar que a tipologia documental se configura como forma pré-definida, possuindo uma estrutura documental exata e regularizara. Sendo assim, não é gratuita a existência de manuais documentais específicos criados com o intuito de regulamentar e padronizar o registro das atividades institucionais, como nos casos dos registros notariais e dos que apresentam fórmulas pré-estabelecidas para se requerer junto à Justiça. A utilização desses manuais tem simultaneamente um sentido prático e formativo, pois funcionam como normalizadores das atividades e regram a produção documental, servindo ao controle dos atos administrativos. Heredia (1991) defende que, para a arquivística, a tipologia documental é a soma da tipologia diplomá- tica com a tipologia jurídico-administrativa. Partindo disso, argumenta que para o arquivista o tipo documental é a somatória do formulário, dos caracteres externos e da informação.

É fundamental a compreensão da diferença existente entre os diversos tipos documentais, pois sua utilização não é aleatória. É a tradução de uma determinada ação com a finalidade de transmitir uma mensagem específica e direcionada. Consequentemente, o emprego do tipo documental, além de estar ligado à questão da autenticidade, está também intimamente ligado ao do valor probatório do documento.

De acordo com o Dicionário de Terminologia Arquivística (1996), a autenticidade é definida como:

A qualidade de um documento quando preenche as formalidades necessárias para que se reconheça sua proveniência, independentemente da veracidade do respectivo conteúdo.

Este conceito algumas vezes causa estranhamento e resistência para sua aceitação em áreas afins, como a de História, por exemplo, mas que atinge seu máximo sentido quando compreendido dentro do contexto de produção documental.

\section{Metodologias de análise}

Do ponto de vista metodológico, a identificação do tipo diplomático parte da espécie, portanto independe das características do conjunto. Essa técnica procura verificar se a espécie e o trâmite empregados correspondem efetivamente ao ato jurídico-administrativo que os gerou.

No que diz respeito à metodologia empregada para a identificação da tipologia documental no campo da Arquivística, esta deve partir obrigatoriamente do princípio da proveniência, buscando verificar se o conjunto homogêneo de atos equivale ao conjunto homogêneo de documentos dele gerados e expressos pela série, como partes constituintes do fundo e de suas subdivisões. A tramitação do documento deve ser idêntica à dos seus correspondentes de série, assim como os prazos de guarda ou eliminação.

Quando se parte da diplomática, o elemento inicial é a decodificação do próprio documento, sendo suas etapas: da anatomia do texto ao discurso, do discurso à espécie, da espécie ao tipo, do tipo à atividade, da atividade ao produtor.

Quando se parte da arquivística, o elemento inicial tem que ser necessariamente a entidade produtora, sendo o percurso: da competência à estrutura, da estrutura ao funcionamento, do funcionamento à atividade refletida no documento, da atividade ao tipo, do tipo à espécie, da espécie ao produtor. 
Segundo Bellotto (2004, p. 61), as metodologias empregadas para a identificação diplomática e identificação tipológica devem ser diferentes, respeitando as particularidades de cada campo que, apesar de distintos, estão intimamente relacionados. Enquanto a diplomática contempla o estabelecimento do nível de veracidade em torno da estrutura e da finalidade do grau jurídico, a tipologia se preocupa com a relação dos documentos com as atividades que os geraram. Para isso, busca identificar os seguintes elementos: a autenticidade em relação à espécie, ao conteúdo e à finalidade; a datação tópica e cronológica; a origem/proveniência; a transmissão/tradição documental; e a fixação do texto, obedecendo sempre a esta sequência.

Já para a identificação dos aspectos tipológicos, é necessário acompanhar uma sequência de procedimentos distinta, na qual deve ser estabelecida antes de qualquer coisa a origem/proveniência do documento; em segundo lugar torna-se essencial vinculá-lo à competência e as funções da entidade acumuladora, seguida pela associação entre a espécie em causa e o tipo documental. Da mesma forma, a identificação do conteúdo e da datação é fundamental.

\begin{tabular}{|c|c|c|}
\hline $\begin{array}{l}\text { Sequência } \\
\text { de ações }\end{array}$ & $\begin{array}{l}\text { Identificação } \\
\text { diplomática }\end{array}$ & $\begin{array}{l}\text { Identificação } \\
\text { tipológica }\end{array}$ \\
\hline $1^{\circ}$ & $\begin{array}{l}\text { Autenticidade } \\
\text { quanto à espécie, } \\
\text { conteúdo e } \\
\text { finalidade }\end{array}$ & $\begin{array}{l}\text { Origem / } \\
\text { Proveniência }\end{array}$ \\
\hline $2^{\circ}$ & $\begin{array}{l}\text { Datação } \\
\text { (tópica e } \\
\text { cronológica) }\end{array}$ & $\begin{array}{l}\text { Vinculação à } \\
\text { competência e } \\
\text { as funções da } \\
\text { entidade } \\
\text { acumuladora }\end{array}$ \\
\hline $3^{\circ}$ & $\begin{array}{l}\text { Origem / } \\
\text { Proveniência }\end{array}$ & $\begin{array}{l}\text { Associação entre } \\
\text { a espécie em } \\
\text { causa e o tipo } \\
\text { documental }\end{array}$ \\
\hline $4^{\circ}$ & $\begin{array}{l}\text { Transmissão / } \\
\text { Tradição } \\
\text { documental }\end{array}$ & Conteúdo \\
\hline $5^{\circ}$ & Fixação do texto & Datação \\
\hline
\end{tabular}

Quadro I. Quadro comparativo entre modelos de identificação documental (1)

O quadro I apresenta a ordem de ações que devem ser adotadas para a aplicação dos métodos de identificação diplomática e de identificação tipológica. Sua comparação permite evidenciar a diferença da abordagem adotada por um ou outro em relação ao seu objeto. É possível perceber, durante o exercício de comparação, que diversos dos elementos constantes em um repetem-se no outro método, consistindo a diferença mais substancial na sequência de procedimentos adotados para a análise.

A alteração da ordem das ações não é irrelevante, muito pelo contrário, ela traz à tona as prioridades e intencionalidades da técnica empregada, como fica evidente nos casos do estabelecimento da proveniência e datação. Em outros aspectos, fica clara a mudança de enfoque dado pelo método, como no caso da diferença existente entre fixação do texto e conteúdo. A autenticidade e a transmissão/tradição documental tão evidenciada pela crítica diplomática, na análise tipológica do documento dão lugar à recuperação da vinculação existente entre competência, funções e atividades da entidade acumuladora, assim como a associação entre a espécie e o tipo documental ganha destaque. Revela-se, desse modo, o deslocamento da perspectiva ao qual o objeto é submetido.

\section{Algumas considerações e possibilidades}

Cabezas Fontanilla (2008), ao fazer um balanço sobre a produção científica espanhola no campo da diplomática diz, ao comentar especificamente do uso da diplomática pela arquivística, que até pouco tempo as investigações que se desenvolviam direcionavam-se ao estudo da documentação senhorial, porém, nos últimos anos, essa tendência vem mudando e documentos que antes eram desprezados, tornaram-se material de estudo, como no caso da documentação produzida pelo Santo Ofício e sua gênese documental. Desponta também o crescente estudo da documentação emanada de organismos judiciais, seus tipos documentais e formas de expedição. Documentos não provenientes de atos jurídicos, e justamente por isso antes fora do campo de análise diplomática, vêm sendo submetidos a critérios diplomáticos e, portanto, contribuindo para o alargamento do campo de estudo.

Realmente, inúmeras são as possibilidades ao se trabalhar com as temáticas da análise tipológica e da diplomática, mas aqui vamos nos restringir a comentar duas referentes ao desenvolvimento de pesquisa e aplicabilidade da técnica.

Uma delas, particularmente na qual venho desenvolvendo pesquisa desde há algum tempo, mais especificamente em relação à documentação proveniente do judiciário (2), recai sobre estabilidade das fórmulas e tipos documentais durante extensos períodos temporais. Algumas instituições se fazem seculares gerando, consequentemente, fundos com datas-limites muito 
extensas, nos quais a produção de determinados tipos documentais pode perpassar vários séculos. Com este intuito, nos parece revelador cotejar a produção documental da entidade produtora com as mudanças e readequações administrativas por ela sofridas em sua história.

Diante da premissa de que todo documento arquivístico é necessariamente o assentamento de uma atividade dentro da função específica que o gerou, o traçar da evolução de determinados tipos documentais, por meio da comparação de sua fórmula em diferentes períodos ao longo dos séculos, pode contribuir para evidenciar certas rupturas e permanências administrativas e sociais, ainda mais quando a documentação em questão se refere a ações tão próximas do cotidiano da população como as produzidas por instâncias judiciais.

Diante da busca por conferir em que medida documentos de um mesmo tipo documental, produzidos em momentos históricos distintos, mantêm o padrão documental sobre o qual se apóiam, o uso de técnicas de análise tipológica ao analisar as séries documentais faz-se fundamental, como também a incorporação de conceitos e métodos da crítica diplomática quando a análise recaí sobre a espécie documental. O emprego de método comparativo entre distintas unidades documentais de uma mesma série documental, produzidas com cem, duzentos ou trezentos anos de diferença, de acordo com caso, combinado com a análise tipológica e diplomática, também proporciona uma conjunção metodológica interessante, do ponto de vista investigativo. O resultado dessa análise, evidentemente, é revelador do modo como a informação é registrada, de acordo com as funções e atividades, pelas estruturas organizacionais responsáveis pela produção documental.

No entanto, a identificação tipológica, assim como a análise de seu formulário e estrutura do tipo documental, não se limita apenas ao estudo de documentos do passado, a massa documental acumulada e aos trabalhos de organização e disponibilização de acervos. Serve também aos estudos da produção documental atual ao identificar os tipos documentais recorrentemente produzidos e suas variações formulares.

$\mathrm{Na}$ administração pública, assim como na privada, a falta de critérios bem definidos para a criação de documentos, gera morosidade e ônus para o desenvolvimento das atividades institucionais. A identificação dessa diversidade é o primeiro passo para normalização e controle da futura produção documental na medida em que pode contribuir para o estabelecimento de padrões documentais a serem adotados, colaborando em muito para a gestão arquivística.

Não pretendemos aqui abarcar todas as tendências investigativas atuais ou esgotar o tema, mas apenas apontar algumas das possibilidades do emprego da critica diplomática e da análise tipológica.

De qualquer maneira, o estabelecimento de critérios de análise que levem em conta a origem dos documentos faz-se imprescindível para contextualização funcional da produção documental. A interpretação das fontes deve passar necessariamente pelo entendimento das causas que motivaram a criação do documento, razão de sua própria existência. Recuperar o contexto funcional da produção documental significa relacionar a existência material do registro com a cadeia de ações que motivaram tal ato e a inter-relação deste com as estruturas organizacionais que lhe respaldam.

Perante isto, destaca-se a importância da compreensão da tipologia documental como instrumento interpretativo dentro da metodologia empregada para análise documental, ocorrendo igualmente com a crítica diplomática. Consequentemente, os resultados obtidos por cada tipo de análise apresentam sentidos diferenciados e demarcam as fronteiras conceituais entre a diplomática tradicional e a tipologia documental.

\section{Notas}

(1) Quadro esquematizado a partir das informações contidas no livro de Heloísa Liberalli Bellotto (2002. p. 21).

(2) Parte deste trabalho pode ser consultado na tese de doutoramento (Rodríguez, 2010), defendida em 2010. A opção do fundo Juízo de Órfãos de São Paulo (15781926, APESP/BR) como objeto de análise, fundamentou-se na possibilidade do acompanhamento das mudanças da estrutura administrativa, em conjunção com a produção documental, sofridas por um mesmo órgão durante longo período temporal. Ao todo, o fundo engloba 348 anos de registros de atividades ininterruptas, permitindo o rastreamento dos modelos empregados para padronizar a criação de documentos. Atualmente, trabalhamos no projeto Estudo comparativo de funções e atividades em instituições análogas: a produção de inventários post-mortem nos Juízo Ordinário e Juízo de Órfãos de São Paulo, séc. XVI-XIX, desenvolvido dentro do Departamento de Ciência da Informação da UNESP/Marília.

\section{Referencias}

Bellotto, Heloísa Liberalli (2004). Arquivo Permanente: tratamento documental. $2^{\mathrm{a}} \mathrm{Ed}$. RJ: Editora FGV.

Bellotto, Heloísa Liberalli (2002). Como fazer análise diplomática e tipológica de documentos de arquivo. SP: APESP/Imprensa Oficial.

Cabezas Fontanilla, Susana (2008). La diplomática general y especial en el marco de los estudios actuales. // VII 
Jornadas Científicas Sobre Documentación Contemporánea (1868-2008). Madrid: Dpto. de Ciencias y Técnicas Historiográficas, Universidad Complutense de Madrid. 9-32. http://www.ucm.es/centros/cont/descar gas/documento11904.pdf (07/08/2010).

Câmara Técnica de Documentos Eletroni-cos/Conarq (dez 2006): Modelo de requisitos para sistemas informatizados de gestão arquivística de documentos: e-ARQ Brasil. RJ: Arquivo Nacional.

Camargo, Ana Maria de Almeida e BELLOTTO, Heloísa Liberalli (coords.) (1996). Dicionário de terminologia arquivística. SP: Associação dos Arquivistas Brasileiros, Núcleo São Paulo; Secretaria de Estado da Cultura.

Delmas, Bruno (2003). Donner à l'image et au son le statut de l'écrit: pour une critique diplomatique des documents audiovisuels. // Bibliothèque de l'École dês Chartes. Paris. 161 (juillet-décembre 2003) 553-601.

Delmas, Bruno (1996). Manifesto for a contemporary Diplomatics: from institutional documents to organic information. // The American Archivist. Chicago. 59:4 (fall 1996) 438-452.

Duranti, Luciana e MacNeil, Heathy (1996). The protection of the integrity of electronic records: an overview of the UBC-MAS Research Project. // Archivaria. 42 (Fall 1996) 46-67.

Duranti, Luciana (1996). Diplomática: usos nuevos para uma antigua ciência. Sevilla: S\&S Ediciones.
Guimarães, José Augusto; Rabello, Rodrigo (2007). A contribuição metodológica da diplomática para a análise documental de conteúdos de arquivos e bibliotecas. / Paleografia e Diplomática no Curso de Arquivologia UFSM. Santa Maria, Brasil: FA-COS/UFSM. 137-157.

Heredia Herrera, Antonia (1991). Descripción y normalización. // Boletín Anabad. 41:2.

Heredia Herrera. Antonia (2007). En torno al tipo documental. // Arquivo \& Administração. RJ: AAB. 3:1/2 (jul/dez.).

Hirtle, Peter B. (2000). Archival authenticity in a digital age. // Authenticity in a digital environment. May 2000. Washington, D.C: Council on Library and Information Resources. 8-23.

Macneil, Heather (2000). Creating and maintaining trustworthy records in electronic systems: archival diplomatic methods. // Trusting records: legal, historical and diplomatic per-spectives. Dordrecht/Boston/London: Kluwer Academic Publishers. 86-112. (The Archivis's Library; 1).

Macneil, Heather (2001). Trusting records in a postmodern world. // Archivaria. 51 (Spring 2001) 36-47.

Rodrigues, Ana Célia (2008). Diplomática Contemporânea como fundamento metodológico da identificação de tipologia documental em arquivos SP: FFLCH/USP. Tese de doutorado.

Rodríguez, Sonia Troitiño. O Juízo de Órfãos de São Paulo: caracterização de tipos documentais (séc. XVI-XX). São Paulo: Universidade de São Paulo Tese de doutorado. http://www.teses.usp.br/teses/. 